\title{
A Dose-Response Analysis of the Reproductive Effects of a Single Gestational Dose of 2,3,7,8-Tetrachlorodibenzo-p-dioxin in Male Long Evans Hooded Rat Offspring ${ }^{1}$
}

\author{
L. E. Gray, Jr., J. S. Ostby, and W. R. Kelce \\ MD 72, Reproductive Toxicology Division, Endocrinology Branch, National Health and Environmental Effects Research Laboratory, \\ U.S. Environmental Protection Agency, Research Triangle Park, North Carolina 27711
}

Received November 14, 1996; accepted May 28, 1997

A Dose-Response Analysis of the Reproductive E ffects of a Single G estational Dose of 2,3,7,8-T etrachlorodibenzo-p-dioxin in Male Long Evans Hooded Rat Offspring. Gray, L. E., J r., Ostby, J.S., and Kelce, W.R. (1997). Toxicol. Appl. Pharmacol. 146, 11- 20.

Male rats exposed in utero to 2,3,7,8-tetrachlorodibenzo-p-dioxin (TCDD) display reduced fertility as a consequence of the direct action of TCDD on the epididymides, as well as delayed puberty and altered reproductive organ weights. The current study provides dose- response data for the reproductive effects of TCDD, administered during pregnancy, with an emphasis on the effects of TCDD on testicular, epididymal, and ejaculated sperm numbers. Long Evans Hooded rats were dosed by gavage with $\mathbf{0}, \mathbf{0 . 0 5}, \mathbf{0 . 2 0}$, or $\mathbf{0 . 8 0 \mu} \mu$ $\mathrm{TCDD} / \mathrm{kg}$ on Day 15 of gestation. After birth, growth, viability, and developmental landmarks were monitored in both male and female offspring. Shortly after puberty (49 and 63 days of age) and at 15 months of age, male offspring were necropsied. G rowth and viability of the pups were reduced only at $0.80 \mu \mathrm{g} \mathrm{TCDD} / \mathrm{kg}$, eye opening was accelerated (all dosage groups), and puberty was delayed (at 0.20 and $0.80 \mu \mathrm{g} \mathrm{TCDD} / \mathrm{kg}$ ). Treated progeny displayed transient reductions in ventral prostate and seminal vesicle weights, while epididymal sperm reserves and glans penis size were permanently reduced. Ejaculated sperm numbers were reduced $(45 \%$ in the 0.8 and by $25 \%$ in the 0.05 and $0.2 \mu \mathrm{g} \mathrm{TCDD} / \mathrm{kg}$ dosage groups) to a greater degree than were cauda or caput/corpus epididymal or testicular (unaffected) sperm numbers. In conclusion, administration of TCDD on Day 15 of pregnancy at $0.05 \mu \mathbf{g} / \mathbf{k g}$ altered eye opening and reduced ejaculated sperm counts, while higher dosage levels also delayed puberty and permanently reduced cauda epididymal sperm reserves. 1997 Academic Press

In humans and rodents, exposure to hormonally active chemicals during sex differentiation can produce pseudoher-

\footnotetext{
${ }^{1}$ The research described in this article has been reviewed by the National Health and Environmental Effects Research Laboratory, U.S. Environmental Protection Agency, and approved for publication. Approval does not signify that the contents necessarily reflect the views and policies of the Agency nor does mention of trade names or commercial products constitute endorsement or recommendation for use.
}

maphrodism (Schardein, 1993; Gray, 1992), resulting in reduced fertility. In addition to estrogenic and antiandrogenic toxicants, perinatal exposure to 2,3,7,8-tetrachlorodibenzop-dioxin (TCDD) causes infertility in male rat progeny at dosage levels well below those that are toxic to adult animals. For example, Khera and Ruddick (1973) reported that prenatal administration of TCDD at $0.5 \mu \mathrm{g} / \mathrm{kg} / \mathrm{day}$ from Day 6 to Day 15 of gestation reduced the viability, growth, and fertility of the Wistar rat offspring without inducing maternal toxicity. In a three generation reproduction study, Murray et al. (1979) found that $0.01 \mu \mathrm{g}$ TCDD $/ \mathrm{kg} /$ day in the diet reduced fertility of F1 and F2 generation Sprague-Dawley rats. However, this dosage level had no effect on the F0 generation. These studies demonstrate that the reproductive system is extremely sensitive to TCDD during perinatal life, with effects occurring at dosage levels that are orders of magnitude below those required to produce reproductive alterations in adult rats (Johnson et al., 1992; Moore et al., 1985).

More recently, Mably et al. (1992a,b,c) reported that administration of a single dose of TCDD on Day 15 of pregnancy altered sexual differentiation of the Holtzman male rat progeny. TCDD treatment at dosage levels ranging from 0.064 to $1 \mu \mathrm{g} / \mathrm{kg}$ altered reproductive hormonal, morphological, and behavioral development including reduced fetal and neonatal serum testosterone levels, shortened anogenital distance, and reduced numbers of testicular and cauda epididymal sperm and sex accessory gland size. Even the lowest dosage level of TCDD altered reproductive development. For example, at $0.064 \mu \mathrm{g}$ TCDD/ $\mathrm{kg}$, latencies to mount and intromission were increased, and sex accessory gland and cauda epididymal weights (down $40 \%$ at this dose) were significantly reduced at 63 days of age. Although subsequent studies (Chen et al., 1993; Gray et al., 1995a; Bjerke et al., 1994a) using Holtzman, Sprague-Dawley, or Long Evans rats exposed to TCDD at $0.7-1.0 \mu \mathrm{g} / \mathrm{kg}$ on gestational Day 15 have been unable to replicate the robust nature of some of the hormonal and behavioral alterations reported by Mably 
et al. (1992a,b,c), a reduction in cauda epididymal sperm reserves has been detected in every study that examined the effects of TCDD treatment on the 15th day of gestation on the male offspring. Subsequently, we reported that gestational exposure to $1.0 \mu \mathrm{g}$ TCDD $/ \mathrm{kg}$ reduced ejaculated sperm counts (down $58 \%$ ) and cauda epididymal sperm reserves to such a degree that fertility was reduced, while in contrast, testicular sperm production was only reduced by $20 \%$ (Gray et al., 1995a). Sommer et al. (1996) observed a similar profile when Holtzman $\mathrm{SD}$ rats were exposed on Day 15 of pregnancy to $1 \mu \mathrm{g}$ $\mathrm{TCDD} / \mathrm{kg}$; male progeny displayed a $46 \%$ reduction in ejaculated sperm numbers, while testis sperm production was reduced by only $28 \%$.

The objectives of the current study were to develop dose-response data for the reproductive effects of gestational Day 15 TCDD administration in male Long Evans (LE) Hooded rat offspring with an emphasis on testicular and epididymal sperm numbers and serum testosterone levels in 49, 63-day-old and middle-aged progeny and ejaculated sperm numbers in adult male offspring. In the present study, LE rats were dosed by gavage with $0,0.05$, 0.20 , or $0.80 \mu \mathrm{g} \mathrm{TCDD} / \mathrm{kg}$ on GD 15 (at the onset of sexual differentiation and the gestational day used in other studies (Mably et al., 1992a,b,c; Gray et al., 1995a)) and viability, growth, and reproductive function of the progeny were monitored. The female siblings of the males utilized in the current study are under separate investigation (Gray et al., in press) because TCDD also alters development of the female progeny (Gray et al., 1995b).

\section{METHODS}

Pregnant LE Hooded rats (12 per group, Charles Rivers, Portage, WI) were dosed by gavage with corn oil (vehicle) or $0,0.05,0.20$, or 0.80 $\mu \mathrm{g}$ TCDD $/ \mathrm{kg}$ in corn oil $(2.5 \mathrm{ml} / \mathrm{kg}$ ) on gestational Day 15 (day after mating is Day 0). Upon receipt, rats were housed individually in clear plastic cages $(20 \times 25 \times 47 \mathrm{~cm})$ with laboratory grade (heat treated to eliminate resins that might induce liver enzymes) pine shavings as bedding (Northeastern Products, Warrensburg, NY). Animals were maintained on a special diet during gestation and lactation (Purina Chow 5008), after which the pups were switched to Purina Rat Chow (5001) and tap water ad libitum in a room with a $14: 10 \mathrm{hr}$ photoperiod (L/D, lights off at 11:00 EST) and temperature of $20-24^{\circ} \mathrm{C}$, with a relative humidity of $40-50 \%$.

Maternal/pup viability and growth were monitored throughout the study. Body weights were taken at 1, 3, 8, 15, and 22 days of age (Day 0 is the day of birth). Litters were randomly reduced on postnatal Day 3 to five males and three females, when possible. Failure to standardize litter sizes in such a manner introduces a great deal of variability in growth rate (twofold increase in variance in body weight at weaning; Gray, unpublished observations) and development of the pups during lactation. Hence, standardization of litter sizes enhances the statistical power of the study. At 13-16 days of age male pups were examined for eye opening and retained nipples/areolas. The presence of nipples/ areolas in male pups would suggest an antiandrogenic action for TCDD. At weaning, pups were housed in unisexual groups with two or three rats/cage.
Offspring. Age and body weight at preputial separation (puberty) were assessed from 34 days of age until complete. Necropsies were conducted at 49 and 63 days of age (the most sensitive ages; Mably et al., 1992a,b,c) and 15 months of age. At 49 and 63 days of age, 10 to 11 males per dose group were necropsied (1 male/litter/age was randomly selected from litters with more than one male). Males were killed by decapitation within $15 \mathrm{sec}$ of removal from their home cage in a separate room, blood was collected for determination of serum testosterone levels, and the males were necropsied. Body, pituitary, adrenal, kidney, liver, ventral prostate, seminal vesicles, testes, and cauda and whole epididymal weights were measured. One epididymis was used to determine caput/corpus and caudal sperm counts as previously described (Gray et al., 1989). Briefly, portions of the epididymis were minced with $2 \mathrm{ml}$ of Medium-199 (M-199); an additional $3 \mathrm{ml}$ of M-199 was added and the sample was incubated for $1 \mathrm{hr}$ at $37^{\circ} \mathrm{C}$. Following incubation, the sample was fixed by adding $15 \mathrm{ml}$ of $10 \%$ phosphate buffered formalin. This sample was subsequently diluted and sperm were counted using a Coulter Counter. Three separate counts of each sample were taken and the mean value was used. In order to determine testicular spermatid head counts (TSHC) the testis was decapsulated, weighed, and placed in $8 \mathrm{ml}$ of cold saline-antibiotic solution $(4.5 \mathrm{~g} \mathrm{NaCl}$, plus $5 \mathrm{ml}$ $100 \times$ PSN antibiotic (Gibco No. 15640-022) per $500 \mathrm{ml}$ of distilled water). The testicular parenchyma was then immediately homogenized using a Tissumizer on ice for $15 \mathrm{sec}$ and sonicated on ice (power $=6$, continuous probe, for $30 \mathrm{sec}$ ), after which $12 \mathrm{ml}$ of $10 \%$ buffered formalin was added. Sperm samples were then counted with a hemocytometer with three trials per sample. For serum testosterone determinations, aliquots of the serum were immediately frozen and stored at $-70^{\circ} \mathrm{C}$ until the samples were assayed for testosterone by RIA (Schanbacher and Ewing, 1975; Cochran et al., 1981; Kelce, 1994).

Remaining male rats were housed two to three per cage with littermates for the remainder of the study. Ejaculated sperm counts were collected from males starting at about 9 months of age by pairing the male for $4 \mathrm{hr}$ during the dark phase of the rat's activity cycle with an intact sexually receptive female rat in a wire bottom cage. At the end of the mating period, the number of copulatory plugs under the cage were counted and the female was necropsied. The female was examined for the presence of a vaginal plug and the uterine contents were collected for sperm enumeration (described in detail by Gray et al., 1995). When a male failed to mate, as evidenced by a lack of a copulatory plug, the sperm data were not collected and the male was remated at a later date. At 15 months of age the male offspring were necropsied, as described above. In order to assure consistency and precision in dissection of the cauda epididymis, this segment was considered to be 14 $\mathrm{mm}$ long. The ventral prostate and one epididymis were used for histological evaluation by Experimental Pathology Laboratories, Inc. (RTP, NC). Tissues were placed in Bouins for $24 \mathrm{hr}$, after which they were rinsed and stored in $70 \%$ alcohol, until being embedded in paraffin, stained with $\mathrm{H}$ and $\mathrm{E}$, and examined for histopathological lesions.

Statistical analysis. Data were analyzed as one-way ANOVAs, using the SAS version 6.08 on the USEPA IBM mainframe. When the study involved collecting data at the same age on more than one pup per litter the data analyzed used litter means rather than individual values. When statistically significant effects $(p<0.05, F$ statistic) were detected in the overall ANOVA model, means were compared using the LSMEANS procedure on SAS (two-tailed $t$ test); $t$ tests being appropriate to test for a priori hypotheses (i.e., that puberty would be delayed, sperm counts reduced and etc., based on the reports of Gray et al. (1995a) and Mably et al. (1992a,b,c)). In addition, the data from this study for the 49-day-old males were pooled with unpublished data from our earlier study which administered TCDD at $1 \mu \mathrm{g} / \mathrm{kg}$ on the 15th day of pregnancy (Gray et al., 1995a) for statistical analysis and graphical representation of the dose-response data. Similarly, ejaculated sperm count data from this study were pooled with the data from our earlier study in order to describe more thoroughly the dose-response relationship of this sensitive endpoint. 
TABLE 1

The E ffects of Gestational Day 15 Administration of Low Doses of TCDD on Growth and Viability of the Offspring during Lactation

\begin{tabular}{lccrc}
\hline Dose of TCDD to the Dam & 0.00 & 0.05 & 0.20 & 0.80 \\
\hline No. of pups: Day 0 & $10.3 \pm 1.0$ & $11.5 \pm 0.8$ & $11.4 \pm 0.6$ & $10.9 \pm 1.0$ \\
No. of pups: Day 3 & $9.8 \pm 1.3$ & $11.5 \pm 0.8$ & $10.5 \pm 1.1$ & $10.5 \pm 0.9$ \\
\% Pup survival: Days 3 to 8 & 100 & $98 \pm 2.5$ & $99 \pm 1.1$ & $93 \pm 3.1^{* *}$ \\
\% Pup survival: Days 3 to 15 & $99 \pm 1.1$ & $98 \pm 2.5$ & $91 \pm 6.3$ & $84 \pm 5.9^{*}$ \\
\% Pup survival: Days 3 to 22 & $99 \pm 1.1$ & $6.27 \pm 0.13$ & $90 \pm 6.3$ & $82 \pm 6.6^{*}$ \\
Body weight (g): Day 0 & $6.48 \pm 0.23$ & $9.69 \pm 0.42$ & $9.42 \pm 0.09$ & $5.80 \pm 0.28^{*}$ \\
Body weight (g): Day 3 & $9.44 \pm 0.21$ & $20.35 \pm 0.61$ & $20.1 \pm 0.58$ & $8.60 \pm 0.40^{*}$ \\
Body weight (g): Day 8 & $20.4 \pm 0.46$ & $36.4 \pm 0.8$ & $37.3 \pm 1.3$ & $17.5 \pm 1.1^{* *}$ \\
Body weight (g): Day 15 & $36.6 \pm 1.0$ & $63.3 \pm 1.2$ & $62.9 \pm 1.5$ & $33.4 \pm 1.5$ \\
Body weight (g): Day 22 & $63.2 \pm 1.2$ & 0 & 0 & $57.8 \pm 2.1^{*}$ \\
\% Eye opening: Day 12 & $2.3 \pm 2.3$ & $3.5 \pm 2.0$ & $50.9 \pm 1.7$ & $2.4 \pm 1.6$ \\
\% Eye opening: Day 13 & $5.7 \pm 4.6$ & $49.8 \pm 11^{*}$ & $12.7 \pm 6.5$ \\
\% Eye opening: Day 14 & $21.6 \pm 6.3$ & $100^{*}$ & $79 \pm 6.6^{* *}$ \\
\% Eye opening: Day 15 & $90 \pm 5.6$ & & $99.3 \pm 0.6^{*}$ \\
\hline
\end{tabular}

Note. All values were calculated and analyzed using litter means. Shaded areas differ significantly from control.

$* p<0.05$.

$* * p<0.01$.

\section{RESULTS}

\section{Maternal and Preweanling Pup Data}

Administration of TCDD did not cause maternal death or reduce weight gain during gestation (data not shown). Embryo/fetal survival from implantation to birth (No. live at birth/implants), the number of live born pups, and survival to postnatal Day (PND) 3 were not reduced by TCDD treatment (Table 1). There were 10-12 pregnant females with viable litters in the $0.05,0.20$, and $0.80 \mu \mathrm{g} \mathrm{TCDD} / \mathrm{kg}$ treatment groups, respectively. However, TCDD did reduce pup survival from PND 3 to PND 22 after standardization of litter sizes by about $15 \%(p<0.05)$ in the $0.80 \mu \mathrm{g}$ TCDD $/ \mathrm{kg}$. Growth was significantly retarded throughout lactation as well in this dosage group (Table 1). The growth retardation persisted through 49 days of age (Table 2a), but was subsequently attenuated, as body weights were not significantly reduced at 63 days or 15 months of age in male progeny. As expected from our earlier study, the percentage of pups that displayed eye opening at 13 days of age was significantly increased by in utero TCDD administration in all dose groups versus control pups (Table 1).

\section{Pubertal Data}

In male rat offspring, TCDD treatment delayed puberty (preputial separation) by more than 2.6 days in the 0.80 ( $p$ $<0.01)$ and by about 1.2 days $(p<0.05)$ in the 0.20 dose group (Table 2a and Fig. 1). Body weight at puberty (weight on the day of preputial separation) was not affected (Table 2a). Prenatal TCDD administration did not produce effects indicative of antiandrogenic activity as treated males did not display retained nipples/areolas or urogenital malformations (hypospadias, undescended testes).

\section{Nonreproductive Organ Weights}

The permanent effects of prenatal TCDD administration in the current study appear to be restricted to the reproductive/ endocrine system. Nonreproductive organ weights (liver, adrenal, kidneys, and brain) were not altered by TCDD treatment in 49- or 63-day-old or 15-month-old progeny. Pituitary weight was decreased by 0.2 and $0.8 \mu \mathrm{g}$ TCDD $/ \mathrm{kg}$ in 49- and 63-day-old males (Table 2a), but not at $1 \mu \mathrm{g} / \mathrm{kg}$ in the previous study (Table 2b) or at 15 months of age in the current study (Table 3).

\section{Effect of TCDD on Androgenic Status}

Even though serum testosterone (T) levels were not reduced by TCDD administration at any dosage level at 49 and 63 days of age, weights of the seminal vesicle plus coagulating gland (with fluids) and ventral prostate, which are T-dependent tissues, were significantly reduced at 49 days of age $(0.80$ and $1.0 \mu \mathrm{g}$ TCDD $/ \mathrm{kg})(($ Tables $2 \mathrm{a}$ and $2 \mathrm{~b}$; Fig. 1). These sex accessory glands were not permanently reduced in size at $0.80 \mu \mathrm{g} / \mathrm{kg}$, as the effect of TCDD treatment was not significant at 63 days of age (Table 2) or at 15 months of age (Table 3 ). In the ventral prostate, acute or subacute acinar inflammation or subacute interstitial inflammation was noted in seven males, but there was no apparent relationship to treatment. When examined at 15 months of age, glans penis weight was 
TABLE 2a

The E ffects of G estational Day 15 Administration of $0,0.05,0.20$, or $0.80 \mathrm{mg}$ of TCDD on Body and Organ Weights and Epididymal Sperm Counts (Whole Epididymis at 49 and Cauda at 63 Days of Age) in Male Progeny, Necropsied at 49 or 63 Days of Age

\begin{tabular}{|c|c|c|c|c|c|c|c|c|}
\hline & \multicolumn{4}{|c|}{ 49-Day-old male offspring ${ }^{a}$} & \multicolumn{4}{|c|}{ 63-Day-old male offspring ${ }^{a}$} \\
\hline & $0.00^{b}$ & $0.05^{b}$ & $0.20^{b}$ & $0.80^{b}$ & $0.00^{b}$ & $0.05^{b}$ & $0.20^{b}$ & $0.80^{b}$ \\
\hline Body weight (g) & $287 \pm 4.6$ & $288 \pm 4.9$ & $282 \pm 6.7$ & $267 \pm 6.6^{*}$ & $381 \pm 9.4$ & $407 \pm 6.5$ & $387 \pm 13.0$ & $376 \pm 11$ \\
\hline Testes weight $(\mathrm{g})$ & $2.71 \pm 0.05$ & $2.69 \pm 0.09$ & $2.67 \pm 0.06$ & $2.53 \pm 0.10$ & $3.36 \pm 0.12$ & $3.44 \pm 0.08$ & $3.30 \pm 0.14$ & $3.22 \pm 0.08$ \\
\hline $\begin{array}{l}\text { Paired epididymal } \\
\text { weight }(\mathrm{mg})\end{array}$ & $336 \pm 9.3$ & $349 \pm 11$ & $331 \pm 12$ & $320 \pm 12$ & $704 \pm 12$ & $744 \pm 18$ & $684 \pm 35$ & $656 \pm 24$ \\
\hline $\begin{array}{l}\text { Cauda epididymis } \\
\text { (mg) }\end{array}$ & $56.9 \pm 2.02$ & $58.7 \pm 3.5$ & $52.7 \pm 2.1$ & $53.7 \pm 2.4$ & $138 \pm 4.2$ & $139 \pm 6.1$ & $125 \pm 4.0$ & $119 \pm 6.3^{*}$ \\
\hline $\begin{array}{l}\text { Epididymal sperm } \\
\text { numbers }\left(\times 10^{6}\right)^{c}\end{array}$ & $21.8 \pm 1.6$ & $16.5 \pm 1.9$ & $18.4 \pm 1.9$ & $14.5 \pm 2.3^{*}$ & $65.6 \pm 3.6$ & $68.4 \pm 3.7$ & $59.3 \pm 4.6$ & $45.6 \pm 5.4 * *$ \\
\hline $\begin{array}{l}\text { Ventral prostate } \\
\text { weight }(\mathrm{mg})\end{array}$ & $162 \pm 7.5$ & $169 \pm 11$ & $142 \pm 11$ & $123 \pm 7.0^{* *}$ & $241 \pm 14$ & $281 \pm 15$ & $240 \pm 15$ & $224 \pm 13$ \\
\hline $\begin{array}{c}\text { Seminal vesicle } \\
\text { weight }(\mathrm{mg})\end{array}$ & $523 \pm 22$ & $552 \pm 37$ & $473 \pm 25$ & $431 \pm 27 *$ & $1055 \pm 29$ & $1077 \pm 54$ & $1054 \pm 36$ & $960 \pm 45$ \\
\hline $\begin{array}{l}\text { Daily sperm } \\
\text { production } \\
\left(\times 10^{6}\right)\end{array}$ & $26.2 \pm 1.3$ & $24.5 \pm 1.2$ & $26.4 \pm 1.2$ & $23.5 \pm 1.9$ & $36.0 \pm 1.3$ & $35.8 \pm 1.8$ & $37.5 \pm 2.4$ & $32.4 \pm 3.0$ \\
\hline $\begin{array}{l}\text { Serum testosterone } \\
\quad(\mathrm{ng} / \mathrm{ml})\end{array}$ & $1.83 \pm 0.14$ & $2.13 \pm 0.32$ & $2.26 \pm 0.57$ & $1.79 \pm 0.20$ & $2.28 \pm 0.42$ & $2.54 \pm 0.40$ & $2.86 \pm 0.63$ & $2.84 \pm 0.47$ \\
\hline $\begin{array}{l}\text { Age at puberty } \\
\text { (days) }\end{array}$ & $40.9 \pm 0.40$ & $40.96 \pm 0.48$ & $42.4 \pm 0.46^{* *}$ & $44.0 \pm 0.27 * *$ & & & & \\
\hline $\begin{array}{l}\text { Body weight at } \\
\text { puberty }(\mathrm{g})\end{array}$ & $219 \pm 3.6$ & $217 \pm 3.6$ & $224 \pm 4.5$ & $227 \pm 3.5$ & & & & \\
\hline Pituitary (mg) & $9.5 \pm 0.25$ & $9.5 \pm 0.28$ & $8.8 \pm 0.26$ & $8.7 \pm 0.28 *$ & $11.0 \pm 0.23$ & $10.9 \pm 0.29$ & $10.2 \pm 0.35^{*}$ & $10.2 \pm 0.24 *$ \\
\hline
\end{tabular}

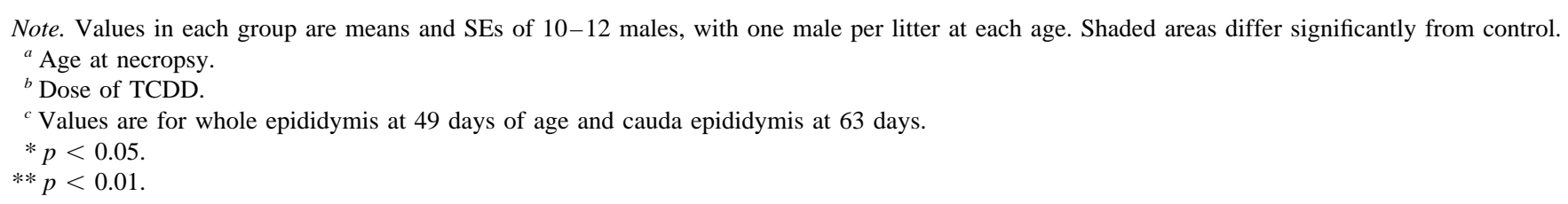

permanently reduced by TCDD treatment at 0.2 and 0.8 $\mu \mathrm{g} / \mathrm{kg}$ (Table 3).

\section{Sperm Numbers, Testis, and Epididymal Effects}

Prenatal TCDD administration permanently reduced cauda epididymal sperm numbers without affecting the testis (Table 2a; Fig. 1). In 49-day-old male rats, total epididymal sperm counts were significantly reduced in the 0.80 dosage group by about $30 \%$ (Table $2 a$ ) and by about $60 \%$ at $1 \mu \mathrm{g}$ TCDD/kg (Table 2b; Fig. 1). At 63 days of age, cauda epididymal weight was significantly reduced by $15 \%$ at $0.8 \mu \mathrm{g} \mathrm{TCDD} / \mathrm{kg}$, while the $9 \%$ reduction in cauda epididymal weight in the $0.20 \mu \mathrm{g}$ TCDD/ $\mathrm{kg}$ dosage group was not statistically significant. Cauda epididymal sperm numbers were significantly reduced by $31 \%$ in the $0.80 \mu \mathrm{g} \mathrm{TCDD} / \mathrm{kg}$ and $10 \%$ (not significant) in the $0.20 \mu \mathrm{g} \mathrm{TCDD} / \mathrm{kg}$ dose group in 63-day-old male progeny (Table 2a; Fig. 1). At middle-age, TCDD exposed male progeny in the 0.2 and $0.8 \mu \mathrm{g} / \mathrm{kg}$ groups both displayed significant reductions in cauda epididymal sperm numbers (down 17\%; Table 3; Fig. 1).

Histopathological analysis of the epididymis revealed a slight increase of chronic inflammation of the epididymis in $29 \%$ of the TCDD-treated males $(5 / 16$ at $0.8,6 /$ 23 at 0.2 , and $7 / 22$ of 0.05 ) compared to $16 \%$ of controls $(3 / 19)$, but this increase was not statistically significant ( $p<0.394$ by Fischer's exact test). One animal in the 0.8 group had moderate hypospermia and diffuse epididymal hyperplasia.

\section{Effect of TCDD on Ejaculated Sperm Counts}

Ejaculated sperm counts were reduced from 137 million in control males to 101 million sperm (down $26 \%$ ) by treatment with $0.05 \mu \mathrm{g} \mathrm{TCDD} / \mathrm{kg}, 103$ million sperm (down $25 \%$ ) by treatment with $0.2 \mu \mathrm{g}$ TCDD/kg, and to 73 million sperm (down $47 \%$ ) at $0.8 \mu \mathrm{g}$ TCDD $/ \mathrm{kg}$ (Table 3). The effect of TCDD treatment was highly significant at $0.80 \mu \mathrm{g} / \mathrm{kg} / \mathrm{day}$ $(p<.006)$. The reductions in ejaculated sperm numbers in 
A. Body Weight
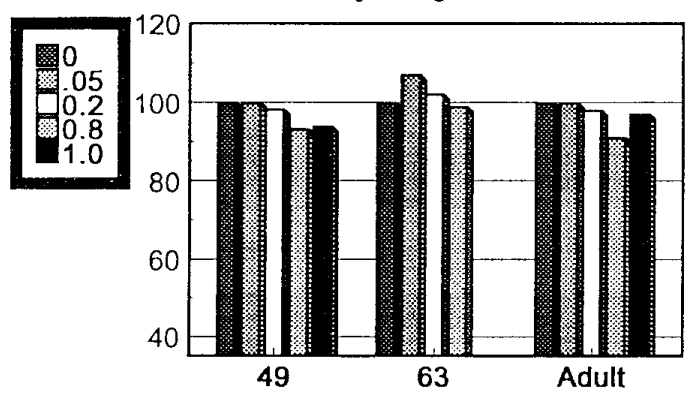

C. Epididymal Sperm Numbers

Whole Epl at 49, Cauda at 63 and as Adults

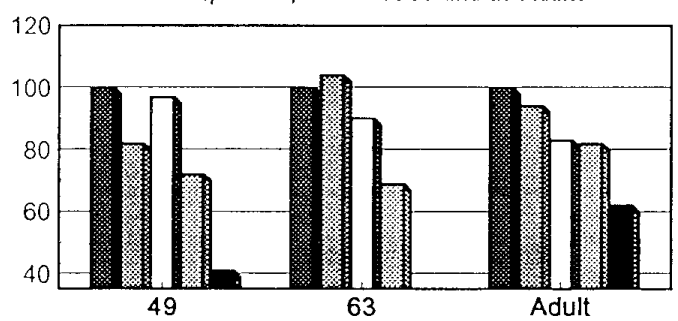

E. Ventral Prostate Weight

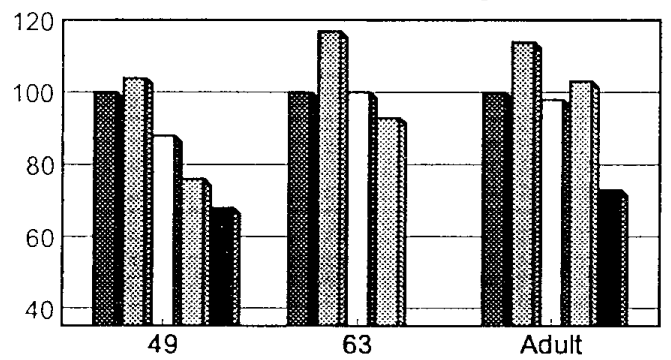

G. Testis Weight

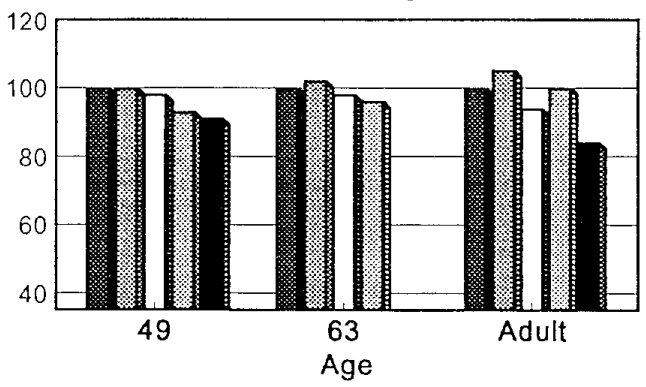

B. Ejaculated Sperm Numbers

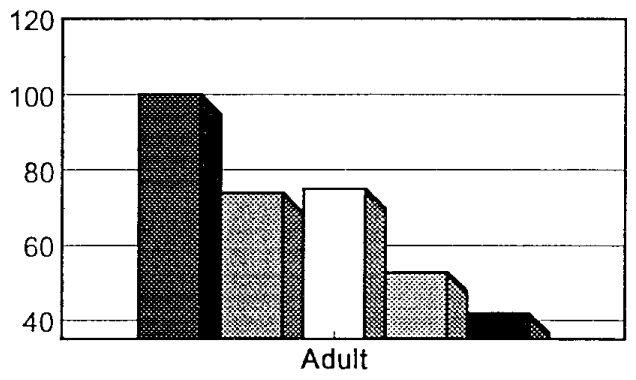

D. Cauda Epididymal Weight

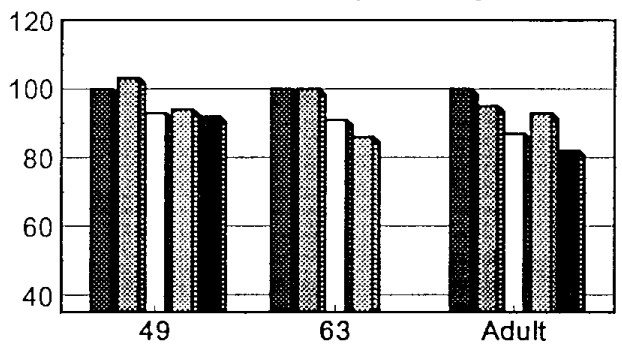

F. Seminal Vesicle Weight

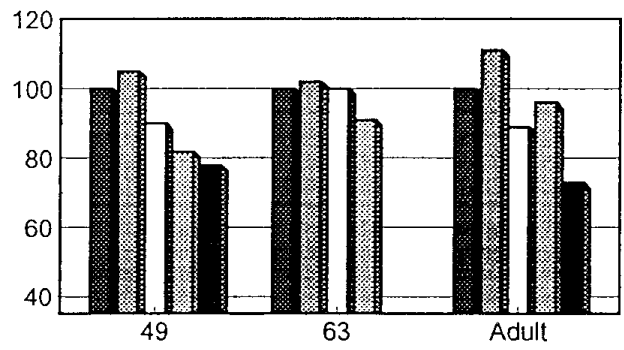

H. Testis Sperm Production

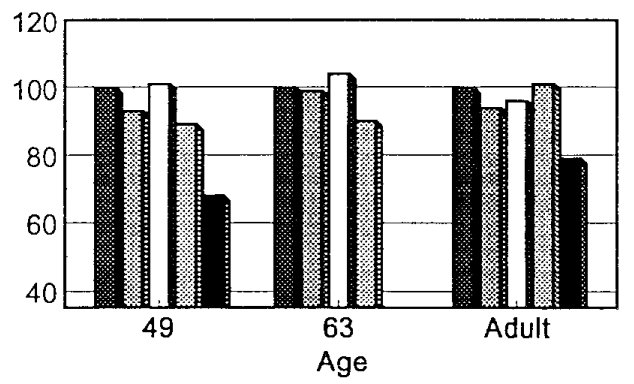

FIG. 1. Reproductive effects of administration of TCDD administered at $0,0.05,0.2,0.8$, or $1.0 \mu \mathrm{g} / \mathrm{kg}$ on the 15 th day of pregnancy in $49-$ and $63-$ day-old and 15-month-old male offspring. Data are expressed as percent of concurrent control at each age so the magnitude of each effect can be compared between different tissues and ages. For ejaculated sperm numbers in adult male offspring (B) when the data were pooled, analyzed, and presented as percentage of the concurrent control value for each study, all values are significantly lower than the control mean by this analysis.

the 0.05 and $0.2 \mu \mathrm{g} / \mathrm{kg}$ dosage groups were significant $(p<$ $0.05)$ when the data from this study were pooled with those from our original study (Gray et al., 1995) by converting the data to a percentage of the concurrent control (Fig. 1). Clearly, a study reexamining the effect of these two low dosage levels of TCDD on ejaculated sperm numbers is warranted. When the ejaculated sperm count data are pooled from the two studies, on a percentage of control basis the values are reduced from $100 \pm 8.5 \%\left(141 \times 10^{6}\right)$, to $74 \pm$ $12.7 \%, 75 \pm 8.8 \%, 53 \pm 9.5 \%$, and $42 \pm 9.2 \%$ in the 0.05 , $0.20,0.80$, and $1.0 \mu \mathrm{g}$ TCDD/kg dosage groups, respectively. In contrast to the ejaculated sperm numbers, the number of 
TABLE 2b

Effects of $1 \mu \mathrm{g}$ TCDD/kg Administered on GD-15 on Endpoints Measured in LE Hooded Male R ats, Necropsied at 49 Days of Age

\begin{tabular}{lccc}
\hline \multicolumn{1}{c}{ Treatment group } & Control & 15 & $p$ \\
\hline Body weight (g) & $273 \pm 5.2$ & $256 \pm 5.5$ & 0.04 \\
Paired testes wt (g) & $2.58 \pm 0.10$ & $2.35 \pm 0.25$ & $\mathrm{~ns}$ \\
Ventral prostate wt (mg) & $164 \pm 12.8$ & $112 \pm 15.2$ & 0.02 \\
Seminal vesicle wt (mg) & $490 \pm 39$ & $382 \pm 36$ & 0.06 \\
Epididymal wt (mg) & $189 \pm 6.9$ & $171 \pm 12$ & $\mathrm{~ns}$ \\
Caudal epididymal wt (mg) & $71 \pm 3.7$ & $65 \pm 3.7$ & $\mathrm{~ns}$ \\
Pituitary weight (mg) & $7.9 \pm 0.18$ & $8.0 \pm 0.47$ & $\mathrm{~ns}$ \\
Daily sperm production & & & \\
$\quad$ TSHC/6.1) $\times 10^{5}$ & $22 \pm 1.0$ & $15 \pm 3.4$ & 0.05 \\
Epididymal sperm count $\times 10^{6}$ & $17.9 \pm 3.0$ & $7.4 \pm 2.7$ & 0.04 \\
Serum testosterone $(\mathrm{ng} / \mathrm{ml})$ & $2.82 \pm 0.46$ & $3.39 \pm 0.98$ & $\mathrm{~ns}$ \\
\hline
\end{tabular}

Note. $n=8$ individuals per group, data were analyzed used individual values. Values are means \pm SEs. Shaded areas differ significantly from control values.

copulatory plugs was not reduced by TCDD administration at any dosage level.

\section{DISCUSSION}

Here, we report that administration of $0.05,0.20$, or 0.80 $\mu \mathrm{g}$ TCDD $/ \mathrm{kg}$ at the onset of the endocrine sensitive phase of sexual differentiation permanently alters reproductive function in male LE Hooded rat progeny. The profile of effects seen in the male and female progeny after in utero TCDD administration appears to be pathognomonic for Ahreceptor agonists, being unlike that described for other endocrine disrupting (i.e., (anti)estrogenic, (anti)androgenic or antithyroidal) chemicals. Exposure to the TCDD-like PCB congener (169) at $1.8 \mathrm{mg} / \mathrm{kg}$ shortly after implantation produces a profile of reproductive alterations identical to that seen with TCDD exposure (Gray and Kelce, 1996). Male rats, exposed to Ah-receptor agonists (AhRAs) in utero, display accelerated eye opening and reduced ejaculated sperm numbers at relatively low dosage levels. Moderate dosage levels of TCDD/PCB 169 delay puberty and reduce cauda epididymal sperm reserves without reducing testis weight or sperm production (Fig. 2). At higher dosage levels, pups are slightly smaller and less viable than are control pups. Female offspring, exposed to low doses of AhRAs in utero, display a unique anomaly (a permanent vaginal thread) and malformations (cleft phallus) (Gray and Ostby, 1995; Gray et al., 1997).

\section{Effect of TCDD on Eye Opening}

The effect of TCDD on the onset of eye opening in 14and 15-day-old pups extends our previous observation to lower dosage levels. Previously, we noted that treatment with $1 \mu \mathrm{g} \mathrm{TCDD} / \mathrm{kg}$ accelerated eye opening by about $20 \%$, in spite of the fact that the TCDD treated pups were growth retarded by about $17 \%$. Similar effects on eye opening and growth have been reported by other investigators using either TCDD (Mably et al., 1992a) or the PCB mixture Aroclor 1254, which contains several TCDD-like PCB congeners

TABLE 3

The E ffects of G estational Day 15 Administration of $0,0.05,0.20$, or $0.80 \mathrm{mg}$ of TCDD on Body and Organ Weights and Epididymal and Ejaculated Sperm Counts in Adult Male Offspring, Necropsied at 15 Months of Age

\begin{tabular}{|c|c|c|c|c|}
\hline Dose of TCDD $(\mu \mathrm{g} / \mathrm{kg})$ & 0.00 & 0.05 & 0.20 & 0.80 \\
\hline Body weight (g) & $741 \pm 23$ & $742 \pm 22$ & $729 \pm 27$ & $677 \pm 24$ \\
\hline Testes weight (mg) & $3993 \pm 76$ & $4193 \pm 68$ & $3770 \pm 119$ & $4004 \pm 104$ \\
\hline Ventral prostate weight (mg) & $463 \pm 38$ & $529 \pm 37$ & $456 \pm 30$ & $478 \pm 30$ \\
\hline Seminal vesicle weight (mg) & $1807 \pm 130$ & $2001 \pm 100$ & $1613 \pm 64$ & $1743 \pm 79$ \\
\hline Glans penis weight (mg) & $145 \pm 2.8$ & $141 \pm 2.1$ & $134 \pm 3.0^{*}$ & $130 \pm 1.8^{*}$ \\
\hline Paired epididymal weight (mg) & $1430 \pm 35$ & $1440 \pm 28$ & $1295 \pm 31 *$ & $1369 \pm 27$ \\
\hline Cauda epididymal weight (mg) & $324 \pm 15$ & $308 \pm 7.1$ & $281 \pm 7.6^{*}$ & $302 \pm 6.2$ \\
\hline Epididymal sperm numbers $\times 10^{6}$ & $238 \pm 9.6$ & $237 \pm 8.7$ & $210 \pm 9.1^{* *}$ & $208 \pm 7.8 * *$ \\
\hline Caput/corpus epididymal sperm numbers $\times 10^{6}$ & $93.5 \pm 2.9$ & $99.5 \pm 4.7$ & $89.2 \pm 4.3$ & $88.8 \pm 2.8$ \\
\hline Cauda epididymal sperm numbers $\times 10^{6}$ & $144.8 \pm 8.3$ & $137 \pm 6.2$ & $120 \pm 8.2 * *$ & $119 \pm 7.5^{* *}$ \\
\hline Ejaculated sperm numbers $\times 10^{6}$ & $137 \pm 19$ & $101 \pm 17$ & $103 \pm 12$ & $73 \pm 13 *$ \\
\hline Number of copulatory plugs & $5.4 \pm 0.5$ & $4.3 \pm 0.3$ & $4.4 \pm 0.4$ & $4.6 \pm 0.3$ \\
\hline Total testis sperm numbers $\times 10^{6}$ & $256 \pm 7.6$ & $241 \pm 14.0$ & $247 \pm 6.7$ & $259 \pm 8.3$ \\
\hline Serum testosterone $(\mathrm{ng} / \mathrm{ml})$ & $1.29 \pm 0.16$ & $1.27 \pm 0.14$ & $1.24 \pm 0.10$ & $1.40 \pm 0.19$ \\
\hline Pituitary weight (mg) & $17.2 \pm 3.0$ & $15.3 \pm 0.9$ & $21.9 \pm 7.7$ & $19.3 \pm 5.3$ \\
\hline
\end{tabular}

Note. Values in each group are litter means and SEs of 15-24 males, with 10-11 litters. Shaded areas differ significantly from control.

$* p<0.01$.

$* * p<0.05$. 
Sperm Numbers as Percent of Control

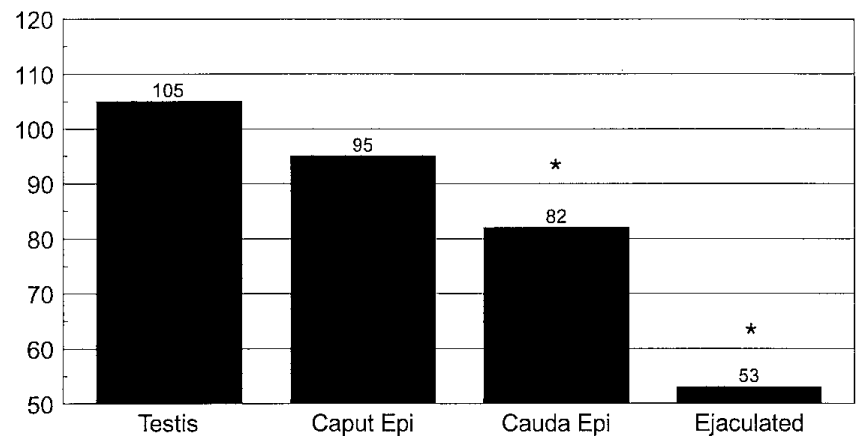

FIG. 2. A comparison of the effects of gestational Day 15 maternal administration of $0.80 \mu \mathrm{g}$ TCDD/kg on sperm numbers in the male offspring during adulthood. Ejaculated sperm numbers are reduced more than are cauda epididymal sperm reserves, while caput and testicular sperm numbers are unaffected by TCDD treatment at this dosage level. The fact that cauda epididymal sperm numbers are reduced even though testicular sperm production is not affected suggests that this portion of the epididymis is functionally compromised as a consequence of direct effects of TCDD on the differentiation of this organ.

(Goldey et al., 1995). For example, Aroclor 1254 treatment at $8 \mathrm{mg} / \mathrm{kg} / \mathrm{day}$ throughout gestation and lactation increases the incidence of eye opening at 15 days of age from $50 \%$ in control pups to $80 \%$ in treated pups, an effect concurrent with reductions in serum thyroxine and triiodothyronine. These observations of accelerated eye opening in growth retarded, hypothyroid rats as a consequence of in perinatal exposure to Ah-receptor agonists are paradoxical, in that retarded growth and hypothyroidism are typically associated with a delay in this developmental landmark.

\section{Serum Testosterone Levels and Puberty}

Mably et al. (1992a) initially reported that in utero TCDDtreatment reduced serum testosterone levels in newborn and peripubertal (69\% decrease at 32 days of age) Holtzman rat pups. However, several investigators have failed to detect alterations in serum testosterone levels in either LE or Holtzman rats (Chen et al., 1993; Gray et al., 1995a; Bjerke et al., 1994a,b,c). We found that in utero administration of 1 $\mu \mathrm{g}$ TCDD $/ \mathrm{kg}$ did not alter serum testosterone levels or LHstimulated in vitro testosterone production at birth or at 49 or 63 days or 15 months of age (Gray et al., 1995a). Chen et al. (1993) reported that treatment with $1 \mu \mathrm{g}$ TCDD $/ \mathrm{kg}$ was without effect on fetal testosterone production in the male Holtzman rat, the strain of rat used by Mably et al. (1992a,b,c). Furthermore, the fact that in utero TCDD treatment does not induce nipple retention, hypospadias, or other morphological abnormalities that are indicative of exposure to antiandrogenic toxicants (Gray et al., 1994; Kelce et al., 1994) suggests that TCDD is not altering the androgenic status of the male pup during perinatal life. Taken together, these results do not support the original hypothesis (Mably et al., 1992a) that alterations in testosterone synthesis or the androgenic status of male rat progeny are responsible for the reproductive alterations seen in TCDD-exposed male rats.

Although serum testosterone levels were not reduced when measured about 10 days after puberty, the age at preputial separation (puberty) was delayed by TCDD-treatment at $0.20,0.80$, and $1.0 \mu \mathrm{g} \mathrm{TCDD} / \mathrm{kg}$. Treatment with $1 \mu \mathrm{g}$ $\mathrm{TCDD} / \mathrm{kg}$ on the 15 th day of pregnancy delayed puberty by 3.6 days, while treatment on Day 8 was less affective, causing a delay of 2.1 days (Gray et al., 1995a). However, it is possible that the delay in preputial separation and the reductions in sex accessory gland size are endocrine-mediated as the studies conducted to date have not provided a comprehensive developmental profile of pituitary and testicular hormones during peripubertal life. Several pituitary and steroidal hormones modulate the effects of testosterone on the rate of pubertal maturation in the male rat. It is worthy of note that pubertal alterations (small penis) have been detected in 11- to 14-year old boys in the Yu-Cheng Cohort exposed to PCDFs and PCBS (Guo et al., 1993).

\section{Sex Accessory Glands}

In our studies, the effects of TCDD on ventral prostate and seminal vesicle weights of 49-day-old rats in the $0.80 \mu \mathrm{g}$ $\mathrm{TCDD} / \mathrm{kg}$ dosage group (ventral prostate down $24 \%$ and seminal vesicle down 18\%) are transient, while at $1.0 \mu \mathrm{g} / \mathrm{kg}$ (ventral prostate down $32 \%$ and seminal vesicle down $22 \%$ ) the reduction in seminal vesicle weights was persistent (Gray et al., 1995a). In contrast to the data presented here, Mably et al. $(1992 \mathrm{a}, \mathrm{b}, \mathrm{c})$ reported larger effects on seminal vesicle and ventral prostate size. In their study, seminal vesicle weight was reduced by $56 \%$ at 49 days of age after exposure to 1 $\mu \mathrm{g} / \mathrm{kg}$, with a lowest observed effect level (LOEL) of 0.16 $\mu \mathrm{g} / \mathrm{kg}$, and ventral prostate weights were reduced by $60 \%$ at 32 days of age, with a LOEL of $0.064 \mu \mathrm{g} / \mathrm{kg}$.

\section{Spermatogenesis}

Although the testis is obviously affected by perinatal TCDD treatment at $1.0 \mu \mathrm{g} / \mathrm{kg}$, it appears that relatively high dosage levels are required to produce a long-term reduction in sperm production as compared to the dosage levels of TCDD that reduce epididymal and ejaculated sperm numbers. Even when affected, the TCDD-induced reduction in testis size and sperm numbers are of lesser magnitude than are the changes in epididymal and ejaculated sperm numbers (Fig. 2). Generally, there is no histological evidence for degeneration of the seminiferous tubules, Sertoli cell abnormalities, or retained spermatids in TCDD-exposed rats. On occasion, we find a TCDD-treated animal (rat and hamster) that displays severe atrophy of the seminiferous tubules with a marked decrease in spermatogenic activity. In such cases, 
the majority of the tubules are lined only with Sertoli cells. Even when spermatogenesis was examined histologically in detail in the Holtzman rat strain, germ cell division and/or degeneration were unaffected by prenatal TCDD treatment (Shinomiya et al., 1994). The magnitude of the effect of perinatal TCDD exposure on spermatogenesis reported here (Fig. 1) is less than that reported for the Holtzman rat by Mably et al. (1992c), who detected a 43\% reduction on Day 49 at $1 \mu \mathrm{g} / \mathrm{kg}$, with a LOEL of $0.064 \mu \mathrm{g} / \mathrm{kg}$ on Day 63 .

\section{The Epididymis}

Clearly, the minimal effect, or lack of effect, of TCDD on sperm production and the absence of any testicular histopathology suggests that one should look for another explanation for the decline in epididymal and ejaculated sperm numbers. In fact, it is now clear that the epididymis is specifically altered by TCDD during sex differentiation. In addition to reduced sperm storage and an increase in epididymal histopathological lesions in rat and hamster offspring (Gray et al., 1995a), Wilker et al. (1996) recently found that administration of $2.0 \mu \mathrm{g} \mathrm{TCDD} / \mathrm{kg}$ on gestational Day 15 caused complete to partial agenesis of the corpus epididymides in approximately a quarter of the animals. In contrast to some of the reproductive effects, effects on the epididymis have been observed in every study in which TCDD was administered at 0.7 to $1.0 \mu \mathrm{g} / \mathrm{kg}$ on gestational Day 15 . The effect of TCDD on epididymal sperm numbers becomes apparent as soon as sperm are detected in the epididymis (i.e., in 49and 63-day-old male progeny), and this effect persists until at least 15 months of age (Table 3). Although qualitatively similar, the effects of TCDD on cauda epididymal sperm numbers and cauda epididymal weight in 63-day-old male rats in this study are of lesser magnitude than those reported by Mably (1992c).

\section{Ejaculated Sperm Numbers}

The reduction in cauda epididymal sperm reserves in TCDD-treated males obviously contributes to the reduction in the number of ejaculated sperm. However, the observation of a greater reduction in ejaculated sperm numbers than numbers of sperm in the cauda epididymis implies that other factors, besides epididymal sperm reserves, may be involved in the reduced number of sperm in the ejaculate (Fig. 2). The fact that the numbers of copulatory plugs and seminal vesicle and ventral prostate weights are not reduced by TCDD administration indicates that the reduced numbers of ejaculated sperm in the uterus does not result from a lack of mating behavior or an inability to ejaculate. However, subtle behavioral alterations, an altered ejaculatory reflex, or poor plug placement could reduce the numbers of sperm ejaculated or their entry into the uterus after ejaculation.

These data demonstrate the utility of a comprehensive assessment of the male reproductive tract after in utero expo- sure to endocrine disrupting chemicals. An assessment of testis sperm numbers and histopathology alone would fail to detect the appropriate NOEL for TCDD-induced reproductive alterations. This observation is not unique. Klinefelter and Hess (in press) have reported that epididymal toxicants act via a variety of mechanisms of action (estrogenic, antiandrogenic, nonhormonal), reducing cauda epididymal reserves without altering spermatogenesis.

Although the present investigation employed Long Evans rats, as alluded to earlier in the discussion, it is not clear that all of the differences between the present study and those of Mably et al. (1992a,b,c), who used Holtzman rats, can be attributed to strain differences in sensitivity to TCDD during development. Other studies using Holtzman rats have also failed to detect some of the effects of TCDD reported by Mably et al. (1992a,b,c). For example, these studies have not seen alterations in serum testosterone levels (Chen et al., 1993), male sex behaviors (Latency to Mount or Intromission) (Bjerke et al., 1994a,b,c), or seminal vesicle, ventral prostate, or total epididymal weights or daily sperm production in 49-day-old male offspring (Wilker et al., 1995). Klinefelter et al., 1995), also failed to detect reductions in total epididymal weight at 49 days of age (Holtzman rats from the same lab as Mably et al. (1992a,b,c) exposed to $1.0 \mu \mathrm{g} \mathrm{TCDD} / \mathrm{kg}$ ). Hence, the biological basis for the differences between the current dose-response study and that conducted by Mably et al. $(1992 a, b, c)$ is unclear. Interestingly, when we administered PCB 169 at $1.8 \mathrm{mg} / \mathrm{kg}$ shortly after implantation, testis weight (down 26\%), sperm production (reduced $32 \%$ ), ventral prostate and seminal vesicle weights (down 50\%), epididymal weight (down 40\%), and sperm reserves (down 66\%) were all reduced in 65-dayold males to the same degree as reported by Mably et al. (1992a,b,c) in their males exposed to $1 \mu \mathrm{g} \mathrm{TCDD} / \mathrm{kg}$.

\section{CONCLUSION}

In conclusion, we observed alterations in reproductive function in male rats after in utero administration of 0.05 , $0.20,0.80$, or $1.0 \mathrm{TCDD} \mu \mathrm{g} / \mathrm{kg}$. A parallel study of the maternal and fetal distribution of $\left[{ }^{3} \mathrm{H}\right] \mathrm{TCDD}$, necropsied 24 $\mathrm{hr}$ after treatment on gestational Day 15, found that all fetal tissues (liver, urogenital tract, head, and body) had equivalent concentrations of 5,13 , or $56 \mathrm{pg} \mathrm{TCDD} / \mathrm{g}$ (wet weight) following treatment with $0.05,0.20$, or $1.0 \mu \mathrm{g} \mathrm{TCDD} / \mathrm{kg}$, respectively (Hurst et al., 1997, 1996). Hence, fetal concentrations of 5 ppt TCDD are associated with accelerated eye opening and a $25 \%$ reduction in ejaculated sperm counts, while 13 ppt TCDD results in several additional developmental reproductive alterations in both male and female (Gray et al., 1997) offspring. The levels of TCDDs (TEQbasis) in the adult human population range over three orders of magnitude from a background level of $13 \mathrm{ppt}$ (wet weight) 
to levels as high as $7000 \mathrm{ppt}$ (DeVito et al., 1995). In the Yu-Cheng cohort the body burden of TCDDs (TEQ) has been estimated at $2130 \mathrm{ppt}$ wet weight (Devito et al., 1995), with placental TCDD concentrations up to $89 \mathrm{ppt}$ wet weight (Schecter et al., 1996). Taken together, these data indicate that our highest dosage level $(1 \mu \mathrm{g} \mathrm{TCDD} / \mathrm{kg})$ produces adverse developmental effects at maternal and placental TCDD levels in the rat that are below those that produce adverse developmental outcomes (reduced birth weight, retarded growth and altered neurobehavioral and reproductive milestones) in humans after accidental high-level gestational exposure (Yu-Cheng) (DeVito et al., 1995; Schecter et al., 1996). Although our lowest dosage level of $0.05 \mu \mathrm{g}$ TCDD/ $\mathrm{kg}$ exceeds the U.S. adult human body burden (TEQ) by about threefold, we should be cautious about concluding that our fetal animals are exposed to levels that are only threefold over human fetal levels for several reasons. First, it is uncertain if TCDD is transferred from the maternal/placental compartment to the human fetus to the same degree that it is in the rat. Second, the bioavailability of TCDD to the fetus at a given maternal body burden may differ depending upon whether TCDD was administered as a single bolus ("pulse"), as in the current study, or by long-term low level exposure, resulting in steady-state conditions. It is clear, however, that the developmental effects of TCDD are not limited to "pulsed" exposures. Long-term low level TCDD administration reduces fertility in exposed rat progeny exposed to $10 \mathrm{ng} / \mathrm{kg} /$ day throughout life (Murray et al., 1979). Another uncertainty in extrapolating the reproductive effects of gestational TCDD administration from the rat to humans lies with the fact that the degree of conservation of function of the Ah-receptor complex during mammalian development is currently unknown as neither the natural ligand nor its role in normal development, if any, has been determined for any species.

\section{ACK NOWLEDGMENTS}

We thank Ora Huey and Cynthia Wolf for their excellent technical assistance in this project and Drs. M. DeVito, L. Birnbaum, W. Setzer, and J. Laskey for their helpful reviews of the manuscript.

\section{REFERENCES}

Bjerke, D. L., and Peterson, R. E. (1994a). Reproductive toxicity of 2,3,7,8tetrachlorodibenzo-p-dioxin in male rats: Different effects of in utero versus lactational exposure. Toxicol. Appl. Pharmacol. 127, 241-249.

Bjerke, D. L., Sommer, R. J., Moore, R. W., and Peterson, R. E. (1994b). Effects of in utero and lactational exposure on responsiveness of the male rat reproductive system to testosterone stimulation in adulthood. Toxicol. Appl. Pharmacol. 127, 250-257.

Bjerke, D. L., Brown, T. J., MacLusky, N. J., Hochberg, R. B., and Peterson, R. E. (1994c). Partial demasculinization and feminization of sex behavior in male rats by in utero and lactational exposure of male rats to $2,3,7,8$ tetrachlorodibenzo-p-dioxin (TCDD) is not associated with alterations in estrogen receptor binding or volumes of sexually dimorphic brain nuclei. Toxicol. Appl. Pharmacol. 127, 258-267.

Chen, S. W., Roman, B. L., Saroya, S., Shinomiya, K., Moore, R. W., and Peterson, R. E. (1993). In utero exposure to 2,3,7,8 tetrachlorodibenzop-dioxin (TCDD) does not impair testosterone production by fetal rat testes. Toxicologist 13, 104.

Cochran, R. C., Ewing, L. L., and Niswender, G. D. (1981). Serum levels of follicle stimulating hormone, prolactin, testosterone, $5 \alpha$-dihydrotestosterone, $5 \alpha$-androstan- $3 \alpha, 17 \beta$-diol, $5 \alpha$-androstan- $3 \beta, 17 \beta$-diol and $17 \beta$ estradiol from male beagle dogs with spontaneous or induced benign prostatic hyperplasia. Invest. Urol. 19, 142-147.

DeVito, M., Birnbaum, L., Farland, W., and Gasiewicz, T. (1995). Comparison of estimated human body burdens of dioxin-like chemicals and TCDD body burdens in experimentally exposed animals. Environ. Health Perspect. 103(9), 820-831.

Goldey, E. S., Kehn, L. S., Lau, C., Rehnberg, G. L., and Crofton, K. M. (1995). Developmental Exposure to polychlorinated biphenyls (Aroclor 1254) reduces circulating thyroid hormone concentrations and causes hearing deficits in rats. Toxicol. Appl. Pharmacol. 135, 77-88.

Gray, L. E. (1992). Chemical-induced alterations of sexual differentiation: A review of effects in humans and rodents. In Advances in Modern Environmental Toxicology: Chemically-Induced Alterations in Sexual and Functional Development: The Wildlife/Human Connection (T. Colborn and C. Clement, Eds.), Vol. XXI, pp. 203-230. Princeton Scientific, New Jersey.

Gray, L. E., Jr., Ostby, J., Ferrell, J., Rehnberg, G., Linder, R., Cooper, R., Goldman, J., Slott, V., and Laskey, J. (1989). A dose-response analysis of methoxychlor-induced alterations of reproductive development and function in the rat. Fundam. Appl. Toxicol. 12, 92-108.

Gray, L. E., Ostby, J. S., and Kelce, W. R. (1994). Developmental effects of an environmental antiandrogen: The fungicide vinclozolin alters sex differentiation of the male rats. Toxicol. Appl. Pharmacol. 129, 46-52.

Gray, L. E., Jr., Kelce, W. R., Monosson, E., Ostby, J. S., and Birnbaum, L. S. (1995a). Exposure to TCDD during development permanently alters reproductive function in male LE rats and hamsters: Reduced ejaculated and epididymal sperm numbers and sex accessory gland weights in offspring with normal androgenic status. Toxicol. Appl. Pharmacol. 131, $108-118$.

Gray, L. E., Jr., and Ostby, J. S. (1995b). In utero 2,3,7,8-Tetrachlorodibenzo-p-dioxin (TCDD) alters reproductive morphology and function in female rat offspring. Toxicol. Appl. Pharmacol. 133, 285-294.

Gray, L. E., Jr., and Kelce, W. R. (1996). Latent effects of pesticides and toxic substances on sexual differentiation of rodents. Toxicol. Indust. Health 12(3/4), 515-531.

Gray, L. E., Jr., Wolf, C., Mann, P., and Ostby, J. S. (1997). In utero exposure to low doses of 2,3,7,8-tetrachlorodibenzo-p-dioxin alters reproductive development in Female Long Evans hooded rat offspring. Toxicol. Appl. Pharmacol. 145, in press.

Guo, Y., Lai, T., Ju, S., Chen, Y., and Hsu, C. (1993). Sexual developments and biological findings in Yu-Cheng Children. Organohalogen Compounds 14, 235-238.

Hurst, C., DeVito, M., Abbott, B., and Birnbaum, L. (1996). 2,3,7,8 tetrachlorodibenzo-p-dioxin (TCDD) in pregnant rats: Distribution to maternal and fetal tissues. Toxicologist 30, 198.

Hurst, C., DeVito, M., Abbott, B., and Birnbaum, L. (1997). Dose-response of (TCDD) distribution in pregnant Long Evans rats. Toxicologist 36, 257.

Johnson, L., Dickerson, R., Safe, S. H., Nyberg, C. L., Lewis, R. P., and Welsh, T. H. (1992). Reduced Leydig cell volume and function in adult rats exposed to $2,3,7,8$-TCDD without a significant effect on spermatogenesis. Toxicology 76, 103-118. 
Kelce, W. R., Monosson, E., Gamcsik, M. P., Laws, S. C., and Gray, L. E., Jr. (1994). Environmental hormone disruptors: Evidence that vinclozolin developmental toxicity is mediated by antiandrogenic metabolites. Toxicol. Appl. Pharmacol. 126, 275-285.

Khera, K. S., and Ruddick, J. A. (1973). Polychlorodibenzo-p-dioxins: Perinatal effects and the dominant lethal test in Wistar rats. In Chlorodioxins-Origin and Fate (E. H. Blair, Ed.), pp. 70-84. American Chemical Society, Washington, DC.

Klinefelter, G. R., Roman, B. L., and Peterson, R. E. (1995). A single gestational TCDD exposure alters protein expression in the adult rat epididymis. Toxicologist 15, 233-234.

Klinefelter, G. R., and Hess, R. A. Toxicology of the male excurrent ducts and accessory glands. In Reproductive and Developmental Toxicology (Korach, Ed.). Dekker, New York, in press.

Mably, T., Moore, R. W., and Peterson, R. E. (1992a). In utero and lactational exposure of male rats to 2,3,7,8-tetrachlorodibenzo-p-dioxin. 1. Effects on Androgenic status. Toxicol. Appl. Pharmacol. 114, 97-107.

Mably, T., Moore, R. W., Goy, R. W., and Peterson, R. E. (1992b). In utero and lactational exposure of male rats to 2,3,7,8-tetrachlorodibenzo-pdioxin. 2. Effects on sexual behavior and the regulation of luteinizing hormone secretion in adulthood. Toxicol. Appl. Pharmacol. 114, 108117.

Mably, T., Bjerke, D. L., Moore, R. W., Gendron-Fitzpatrick, A., and Peterson, R. E. (1992c). In utero and lactational exposure of male rats to 2,3,7,8-tetrachlorodibenzo-p-dioxin. 3. Effects on spermatogenesis and reproductive capability. Toxicol. Appl. Pharmacol. 114, 118-126.

Moore, R. W., Potter, C. L., Theobald, H. M., Robinson, J. A., and Peterson, R. E. (1985). Androgenic deficiency in male rats treated with 2,3,7,8tetrachlorodibenzo-p-dioxin. Toxicol. Appl. Pharmacol. 79, 99-111.
Murray, F. J., Smith, F. A., Nitschke, K. D., Humiston, C. G., Kociba, R. J., and Schwetz, B. A. (1979). Three-generation reproduction study in rats given 2,3,7,8-tetrachlorodibenzo-p-dioxin (TCDD) in the diet. Toxicol. Appl. Pharmacol. 50, 241-252.

Schardein, J. L. (1993). Hormones and hormonal antagonists. In Chemically Induced Birth Defects, pp. 271-339. Dekker, New York.

Schecter, A., Startin, J., Wright, C., Papke, O., Ball, M., and Lis, A. (1996). Concentrations of polychlorinated dibenzo-p-dioxins and dibenzofurans in human placental and fetal tissues from the U.S. and Placentas from Yu-Cheng Exposed mothers. Chemosphere 32(3), 551-557.

Schnabacher, B. D., and Ewing, L. L. (1975). Simultaneous determination of testosterone, $5 \alpha$-androstan- $17 \beta$-ol-3-one, $5 \alpha$-androstan- $3 \alpha, 17 \beta$-diol, and $5 \alpha$-androstan- $3 \beta, 17 \beta$-diol in plasma of adult male rabbits by radioimmunoassay. Endocrinology 97, 787-792.

Shinomiya, K., Bjerke, D. L., Moore, R. W., Hess, R. A., Cooke, P. S., Zucker, R. W., and Peterson, R. E. (1994). Effects of in utero and lactational exposure to 2,3,7,8-tetrachlorodibenzo-p-dioxin (TCDD) on spermatogenesis in rats. Toxicologist 14, 382 .

Sommer, R., Ippolito, D., and Peterson, R. (1996). In utero and lactational exposure of the male Holtzman rat to 2,3,7,8-tetrachlorodibenzo-p-dioxin: Decreased epididymal and ejaculated sperm numbers without alterations in sperm transit rate. Toxicol. Appl. Pharmacol. 140, 146-153.

Wilker, C. E., Welsh, T. H., Jr., and Johnson, L. (1995). Effects of perinatal exposure to 2,3,7,8-tetrachlorodibenzo-p-dioxin (TCDD) on sertoli cell number and testicular function. Toxicologist 15, 293.

Wilker, C., Johnson, L., and Safe, S. (1996). Effects of developmental exposure to indole-3-carbinol or 2,3,7,8-tetrachlorodibenzo-p-dioxin on reproductive potential of male rat offspring. Toxicol. Appl. Pharmacol. 141, 68-75. 